\title{
Inference Rule of Collision Risk Index based on Ship Near-Collision via Adaptive Neuro Fuzzy Inference System
}

Ho Namgung*

Graduate School of Maritime Transportation System, Mokpo National Maritime University, Mokpo, KS005, Republic of Korea

\begin{tabular}{l} 
A R T I C L E I N F O \\
\hline Article history: \\
Received: 03 June, 2019 \\
Accepted: 17 July, 2019 \\
Online :21 July, 2019 \\
\hline Keywords: \\
Near-collision \\
Ship domain \\
Collision Risk Index \\
ANFIS
\end{tabular}

A B S T R A C T
Collision risk index has been studied as the required quantitative values for decision-
making of collision avoidance between ships. Recently, inference methods of the collision
risk were proposed on the basis of the fuzzy theory because of being possible to collect data
in real time. Existing fuzzy inference system was composed of only simulation results using
virtual navigation situation. In this study, we obtained the fuzzy inference rule based on
ship near-collision data via the adaptive neuro fuzzy inference system. Proposed fuzzy
inference rule expressed various collision risk index in order that a ship could avoid
collision with an encounter ship at appropriate distance and time. It would support for
navigators to make an appropriate decision for collision avoidance with encounter ships.

\section{Introduction}

Despite the efforts to prevent accidents, marine accidents has been occurring without interruption. According to the statistics of KMST(Korean Maritime Safety Tribunal), 10,991 marine accidents have occurred in the last five years from 2014 to 2018. Out of these accidents, 1,132 marine accidents have occurred in collision resulting from lack of look-out and violation of CORLEGs(International Regulations for Preventing Collisions at Sea) [1]. Accordingly, collision accidents can cause structural hazard, loss of human life and property, and ocean pollution due to oil and cargo spills. Thus, since the demand on system to support the safe navigation of ships has been increased, collision avoidance algorithm has been proposed.

Collision avoidance algorithm starts from assessing the collision risk. In order to assess the collision risk in the early days, the concept of a ship domain proposed by [2] was used to assess the collision risk. This concept is succeeded by [3], [4] and [5] in several shapes, the methods of determining ship domains have evolved with time [6,7,8-10]. Nonetheless, it still doesn't contain time-related information.

Since it has been possible to obtain DCPA(Distance of the Closest Point of Approach) and TCPA (Time to the Closest Point of Approach) in real time, inference method of the CRI(collision risk index) on the basis of the fuzzy theory has been proposed. In [11], the author connected DCPA and TCPA to the CRI using interviews of navigators by showing virtual navigation situation on

*Corresponding Author: Ho Namgung, Email: ngh2009@mmu.ac.kr www.astesj.com

https://dx.doi.org/10.25046/aj040419 simulator. In [12], the authors reconstructed the FIS (Fuzzy Inference System) using non-dimensionalized DCPA and TCPA. In [13], the researchers calculated the CRI by including VCD (Variance of Compass Degree) into input parameter proposed by Lee and Rhee.

On the basis of the proposed FIS $[11,12,13]$, various studies have been conducted. In [14], the author designed an estimation algorithm of the collision risk among approaching multiple ships by using the fuzzy theory, and verified performance on the basis of the AIS (Automatic Identification System) maritime traffic data. In [15], the author proposed an evaluation algorithm of the collision risk in order that VTSO (Vessel Traffic Service Operator) was able to analyze the collision risk among ships in advance. In [16], the author proposed a model of predicting ship collision risk based on the FIS considering the general patterns of collision avoidance. Furthermore, the FIS has been applied to collision avoidance system in the field of development for an USV(Unmanned Surface Vehicle). The USV developed for multipurpose of ocean observation and surveillance could flexibly change an action space according to the collision risk, which was inferred by using obstacle information on a basis of fuzzy inference [17]. In [18], the researcher used the FIS as a point of time for generating and sending messages in order that efficient information exchange for collision avoidance was possible between autonomous ship and manned ship.

But the proposed FIS $[11,12,13]$ had the limitation which was relied on the empirical factors of navigators. Hence, in [19], the 
author suggested the FIS considering ship's characteristic in virtual navigation situation on simulator without interviews of navigators. Nonetheless, because of membership functions and rules determined by simulation results, the existing FIS still have significant limitation not reflecting on information of actual collision situation between ships.

To overcome the limitation of the existing FIS [11,12,13,19], this study proposed an improved fuzzy inference rule by learning actual near-collision data extracted from the AIS via ANFIS (Adaptive Neuro Fuzzy Inference System). Section II described inference methods of the collision risk using the FIS and decision of near-collision. Section III suggested the fuzzy inference rule obtained by learning ship near-collision data via ANFIS. Subsequently, performance of the proposed FIS comparing with the existing FIS was validated and discussed in section IV. Finally, a summary of the work and the conclusion drew in section V.

\section{Materials}

\subsection{Calculation of the CRI using FIS}

The FIS inferred the CRI based on the fuzzy theory using DCPA and TCPA. DCPA referred to a minimum distance through a target ship when own-ship and a target ship were encountered. TCPA was an expected time to arrive at the point where DCPA occurred at the ship's present location. Figure 1 is presented that ships $V_{1}$ and $V_{2}$ passed the minimum distance between ships at TCPA $t_{\mathrm{c}}$. The time from current time to $t_{\mathrm{c}}$ was TCPA, and the distance between own-ship and a target ship at estimated time from the $t_{\mathrm{c}}$ was DCPA.

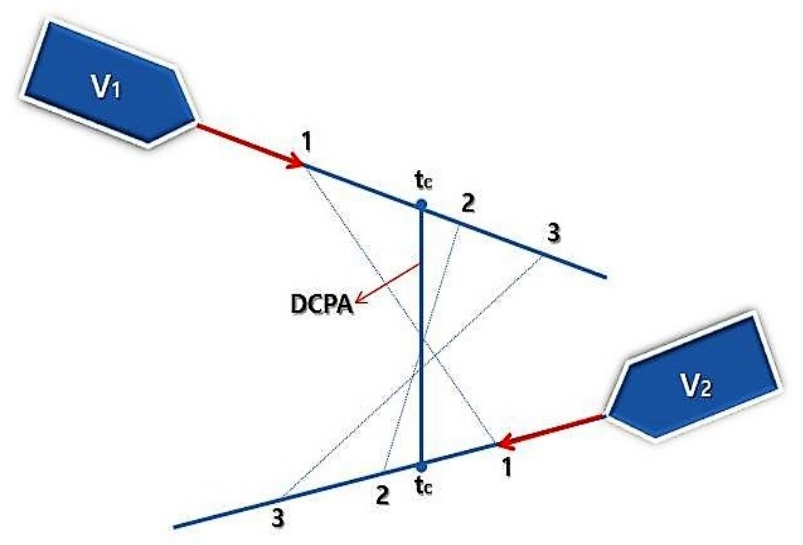

Figure 1: Calculation DCPA and TCPA

Figures 2 and 3 show the fuzzy membership function of $\mathrm{TCPA} /(L / V)$ and DCPA $/ L$, where $L$ was a length of ship and $V$ was a ship speed. In order to increase precise on the FIS, letting DCPA and TCPA to be dimensionless by using a length and a speed of ship was conducted[12]. The CRI can be expressed as values from -1 to 1 . Negative values in TCPA mean that a target ship passed through own ship, i.e., safe situation by being out of the collision risk.

Inference rule of state variables used in the FIS are Small (S), Medium (M), B (Big), P (Positive), and N (Negative). Table 1 shows a part where collision risk was determined in order that an input and an output can express the inference rule as a two- dimensional matrix. In other words, it is determined by a condition part of the $i-$ th inference rule out of all the inference rules. The $\mathrm{CRI}$ at the conclusion as numerals in the fuzzy inference table as show in equation (1).

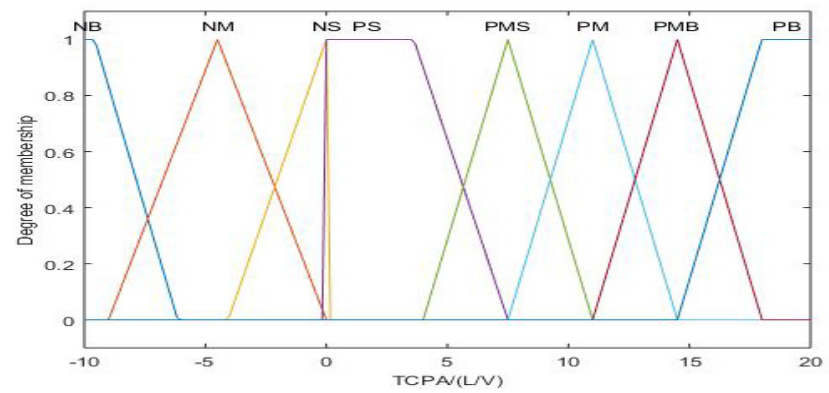

Figure 2: Fuzzy membership function of TCPA/ $(L / V)$

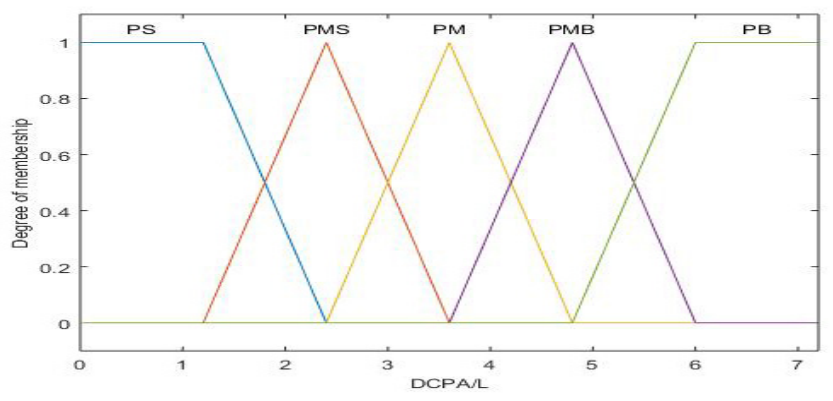

Figure 3: Fuzzy membership function of DCPA $/ L$

$$
\text { Collision Risk }(\mathrm{CR})=\frac{\sum_{i=1}^{n} C R_{i} \cdot a_{i}}{\sum_{i=1}^{n} a_{i}}
$$

Where,

$n=$ number of reasoning rules,

$C R_{i}=$ singleton value of conclusion part of $i-$ th rule,

$a_{i}=$ contribution factor of conditional part of $i-$ th rule.

Table 1: Fuzzy inference table

\begin{tabular}{|l|c|c|c|c|c|c|c|c|c|}
\hline \multicolumn{2}{|c|}{ Division } & \multicolumn{7}{|c|}{ TCPA $(L / V)$} \\
\cline { 3 - 10 } & NB & NM & NS & PS & PMS & PM & PMB & PB \\
\hline \multirow{4}{*}{$\begin{array}{l}\text { DCPA } \\
/ L\end{array}$} & PS & -0.2 & -0.6 & -1.0 & 1.0 & 0.8 & 0.6 & 0.4 & 0.2 \\
\cline { 2 - 10 } & PMS & -0.2 & -0.2 & -0.6 & 0.8 & 0.6 & 0.4 & 0.2 & 0.2 \\
\cline { 2 - 10 } & PM & -0.2 & -0.2 & -0.2 & 0.6 & 0.4 & 0.2 & 0.2 & 0.2 \\
\cline { 2 - 10 } & PMB & -0.2 & -0.2 & -0.2 & 0.4 & 0.2 & 0.2 & 0.2 & 0.2 \\
\cline { 2 - 9 } & PB & -0.2 & -0.2 & -0.2 & 0.2 & 0.2 & 0.2 & 0.2 & 0.2 \\
\hline
\end{tabular}

A point of time for an action of collision avoidance[12,13,19] was determined as follows. In case of a give-away ship, more than 0.6 of the CRI mean an action of collision avoidance. A stand-on ship takes an action of collision avoidance in case of more than 0.8 .

\subsection{Decision of Ship Near-Collision}

Because the number of actual collision accidents was very small, it was significantly difficult to construct a model for evaluating the collision risk based on previous marine accidents [20]. Therefore, near-collision, which was a situation in which there was the danger of collision between ships approaching each other, but with no collision eventually occurring, either due to 
deceleration, or evasion by the change of course, was used. In order to detect a number of near-collision, ship domain was utilized for decision of near-collision as criteria not overlapped between ship domains $[21,22]$. Thus, in this study, near-collision was decided according to proposed methods using ship domain.

Ship domain [2] size with ellipse can be divided into two types as follows. In the sufficient sea area to freely navigate with 10 to 16 knots, the ship domain was composed of $8 L$ and $3.2 \mathrm{~L}$, where $L$ is ship length. In the constrained sea area such as narrow channel or harbour, the ship domain was composed of $6 L$ and $1.6 L$ by reducing speed until 6 to 8 knots. Figure 4 shows ship domain size[2].

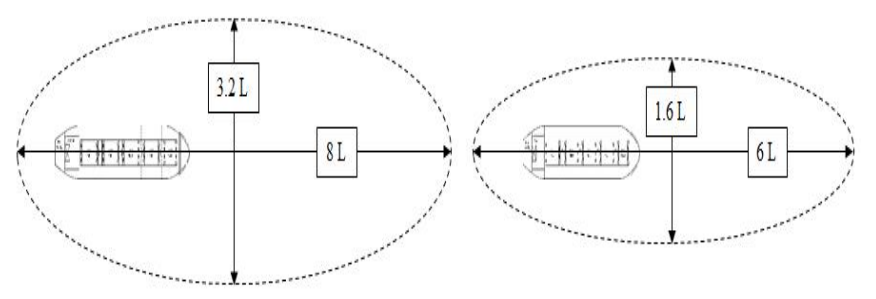

Figure 4: Ship domain size

Ship near-collision based on ship domain with ellipse can be decided in shown as Figure 5.

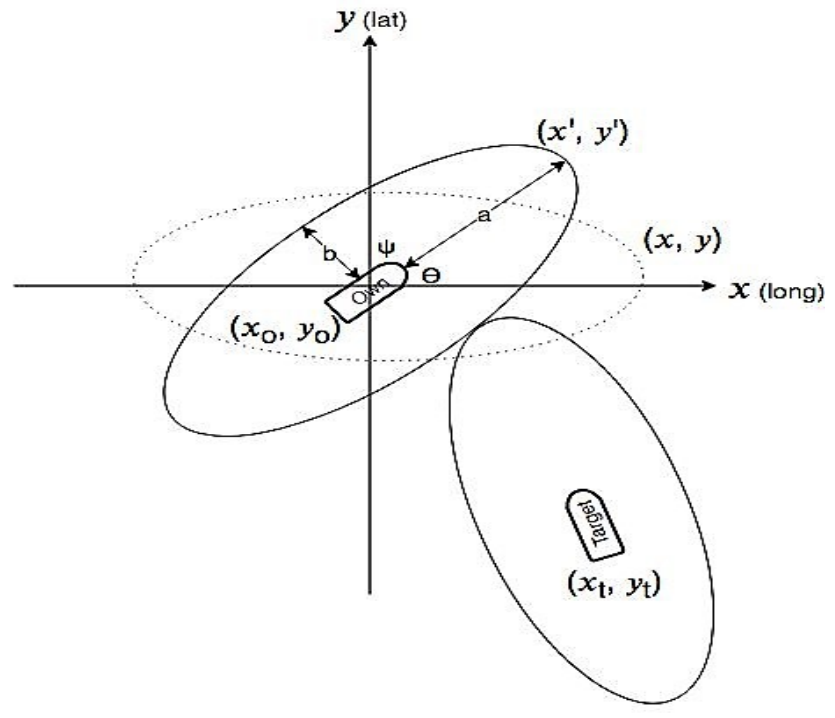

Figure 5: Near-collision between ship's ellipse dimensions

Own ship's ellipse area is parallel to the axis $x$ at the position $\left(x_{O}, y_{O}\right)$, and can be expressed with a long radius $(a)$ and a short radius $(b)$ in the shape of a dotted line. As an ellipse of position is able to be changed in accordance with own ship's course, rotation of ellipse is necessary corresponding to course. A long radius $a$ and angle of intersection $\theta$ of bow direction on the axis $x$ are decided according to ship course angle $\varphi$ as equation (2). Calculation of rotated own ship's ellipse follows equation (3).

$$
\theta=\left\{\begin{array}{l}
\left|90^{\circ}-\varphi\right|\left(\varphi \leq 180^{\circ}\right) \\
\left|270^{\circ}-\varphi\right|\left(\varphi \geq 180^{\circ}\right)
\end{array}\right.
$$

$$
\begin{gathered}
\frac{\left(\cos \theta \times\left(x^{\prime}-x_{O}\right)+\sin \theta \times\left(y^{\prime}-y_{O}\right)\right)^{2}}{\left(a \times L_{O}\right)^{2}}+ \\
\frac{\left(\sin \theta \times\left(x^{\prime}-x_{O}\right)+\cos \theta \times\left(y^{\prime}-y_{O}\right)\right)^{2}}{\left(b \times L_{O}\right)^{2}}=1
\end{gathered}
$$

\section{Inference Rule based on Near-Collision via ANFIS}

\subsection{Procedure for Configuration of the Fuzzy Inference Rule}

Procedure for configuration of the fuzzy inference rule presented in Figure 6 can be divided into four steps. A defined action of collision avoidance was defined in first step. Second step designated appropriate distance corresponding to an action of collision avoidance. Third step enlarged an area of the ship domain based on designated distance, and extracted DCPA, TCPA and CRI when ship domain enlarged by level was overlapped. The fuzzy inference rule by learning ship near-collision data via ANFIS was suggested in fourth step.

\subsection{Set on the Collision Risk Index}

The CRI was set by enlarging the ship domain corresponding to appropriate distance for collision avoidance through definition of an action of collision avoidance by level.

First step defined an action of collision avoidance corresponding to level, and set appropriate distance by level. According to the classification of encounter situations[23,25], an action of collision avoidance was divided into Collision(C), Dangerous(D), Threat(T) and Attention(A). Table 2 defines an

\begin{tabular}{|c|c|}
\hline Level & Definition \\
\hline $\begin{array}{l}\text { Collision } \\
\text { (C) }\end{array}$ & - Both ships almost have collision \\
\hline $\begin{array}{l}\text { Dangerous } \\
\text { (D) }\end{array}$ & $\begin{array}{l}\text { Both ships must conduct the best cooperation } \\
\text { an action for collision avoidance }\end{array}$ \\
\hline $\begin{array}{l}\text { Threat } \\
\text { (T) }\end{array}$ & $\begin{array}{l}\text { A give-way ship must conduct an action of } \\
\text { collision avoidance } \\
\text { - A stand-on ship can take an action for } \\
\text { collision avoidance }\end{array}$ \\
\hline $\begin{array}{l}\text { Attention } \\
\quad \text { (A) }\end{array}$ & $\begin{array}{l}\text { A give-way ship must conduct an action of } \\
\text { collision avoidance } \\
\text { A stand-on ship must keep own course and } \\
\text { speed }\end{array}$ \\
\hline
\end{tabular}
action of collision avoidance by level.

Table 2: Definition of an action of collision avoidance by each level

In order to set appropriate distance according to the defined level, it is necessary to take into consideration a give-way ship and a stand-on ship's distance for an action of collision avoidance.COLREGs requested a specified light intensity to show the minimum distance of the ship lighting[23]. The mast light is 6 $\mathrm{nm}$ (nautical miles), side light is $3 \mathrm{~nm}$ and stern light is $3 \mathrm{~nm}$. Comparing the minimum distance of the ship lighting with an encounter situation for an action of collision avoidance, the mast light and the side light are able to be checked on head-on and crossing situation, and the stern light are able to be checked on overtaking situation. 


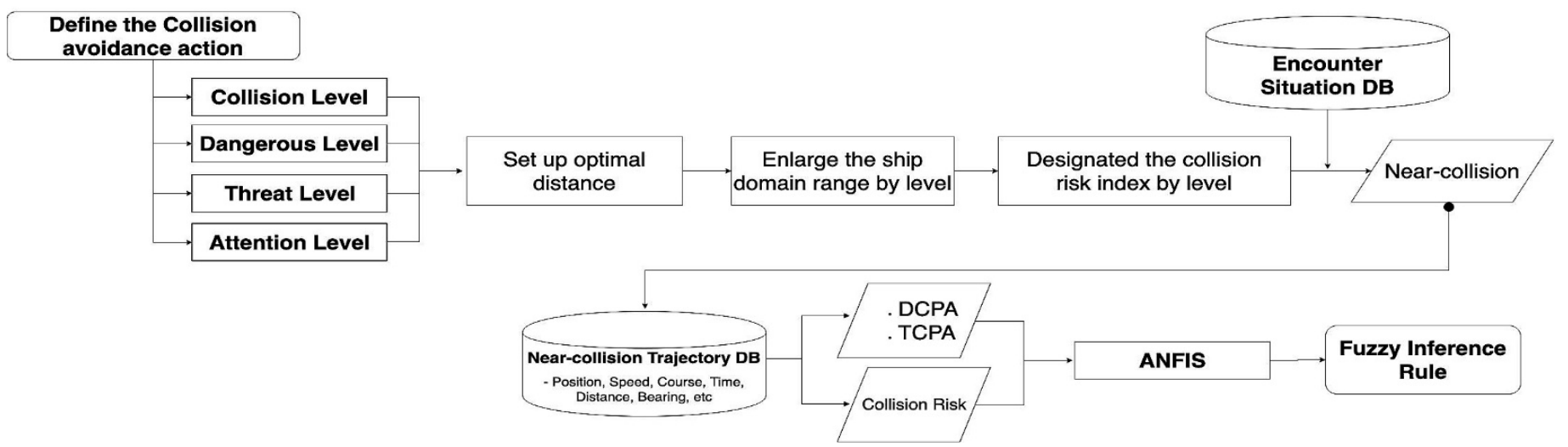

Figure 6: Procedure for configuration of fuzzy inference rule using ship near-collision data

Results of navigator's interviews[24] showed $6 \mathrm{~nm}, 3 \mathrm{~nm}$ and $1 \mathrm{~nm}$ on the head-on situation, crossing and overtaking situation, and the minimum safe distance. Cockcorft, A. and Lameijer, J.N.F.,(2011) [25] advised the minimum safe distance for collision avoidance as $1 \mathrm{~nm}$ in sight of one another and $2 \mathrm{~nm}$ in restricted visibility. And, for a collision situation involving two power-driven ships, the minimum distance suggested for an action of collision avoidance were 2 to $3 \mathrm{~nm}$.

Therefore, an action distance of collision avoidance for Collision(C) level was not set due to occurred situation of collision between ships. An action distance for Dangerous(D) level was set as $1 \mathrm{~nm}$ in order to pass safely between ships through both ship's cooperation navigation. An action distance for Threat(T) level was set as $2 \mathrm{~nm}$ in order that a stand-on ship takes an action of collision avoidance by continuously observing an action of a give-way ship's collision avoidance. At this distance, a give-way ship still has an obligation for collision avoidance. An action distance of Attention(A) was set $3 \mathrm{~nm}$ due to initial beginning of the collision risk between ships.

Second step sets the CRI corresponding to enlarged the ship domain based on designated distance by level. In order to enlarge the ship domain, we used the ship domain $(8 L \times 3.2 L)[2]$ as standard, considering limited ship speed suggested in each sea area. The standard ship length was set as 70 meters due to having different lengths[2].

In case of overlapping the ship domain $(8 L \times 3.2 L)$ set in encounter ships, each ship had extra distance $0.3 \mathrm{~nm}$. At this time, the sum of extra distance was $0.6 \mathrm{~nm}$. This was due to actual collision accident was not occurred. However, since distance of the overlapping ship domain was less than the minimum safe distance $1 \mathrm{~nm}$, it could mean that both ships almost had collision. Hence, ship domain $(8 L \times 3.2 L)$ was set corresponding to Collision(C) level. Based on this approaching methods, ship domain size was adjusted corresponding to designated distance by level.

The existing FIS had the range of the CRI from -1.0 to 1.0. But in this study, we composed of the range of the CRI from 0.0 to 1.0 except for negative sign. The CRI of Attention(A) level was set 0.0 due to initial beginning of the collision risk between ships. Other levels were designated by dividing 1.0 to the three parts. Accordingly, the CRI of Collision(C) level was 1.0 due to the meaning of having collision between ships, and Dangerous(D) level and Threat(T) level were set as 0.66 and 0.33 due to gradually increasing the CRI by times. Table 3 shows the range of the CRI, ship domain size and the minimum safe distance by proposed level. Overlapping situation between ship domains is presented in Figure 7.

Table 3: The range of the CRI, ship domain and safe distance by proposed level

\begin{tabular}{|c|c|c|c|}
\hline Level & NM & Ship domain & CRI \\
\hline $\mathbf{C}$ & - & $8 \mathrm{~L} \times 3.2 \mathrm{~L}$ & 1.0 \\
\hline D & $\begin{array}{l}0.6<\mathrm{NM} \\
\leq 1.0\end{array}$ & $13.2 L \times 5.28 L$ & $0.66 \leq \mathrm{CRI}<1.0$ \\
\hline $\mathbf{T}$ & $\begin{array}{l}1.0<\mathrm{NM} \\
\leq 2.0\end{array}$ & $\begin{array}{l}26.4 \mathrm{~L} \\
\times 10.56 \mathrm{~L}\end{array}$ & $\begin{array}{l}0.33 \leq \mathrm{CRI} \\
<0.66\end{array}$ \\
\hline A & $\begin{array}{l}2.0<\mathrm{NM} \\
\leq 3.0\end{array}$ & $\begin{array}{l}39.6 L \\
\times 15.84 L\end{array}$ & $0.0 \leq \mathrm{CRI}<0.33$ \\
\hline
\end{tabular}

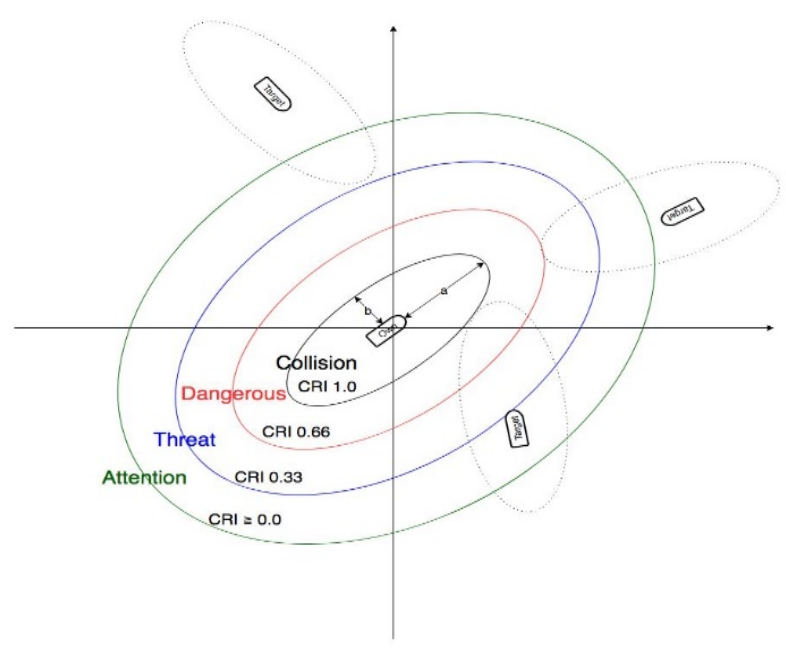

Figure 7: Overlapping situation of ship domain by proposed level

\subsection{Ship's Trajectory Data by Level}

By setting enlarged ship domain based on Collision(C) level to both ships, ship's trajectory data were extracted when overlapped. This was for comparing and analyzing the information generated from initial beginning of the collision risk to occurring to nearcollisions. At this time, ship domain of both ships were set by having the same size in order that enlarged ship domain applied to both ships corresponded to the designated distance when overlapped. To collect ship's near-collision data, Mokpo sea area 
was designated. 97 cases out of a total of 154 ships had encounter situations. Results of near-collision by setting ship domain $(8 \mathrm{~L} \times 3.2 \mathrm{~L})$ as Collision(C) level was a total of 49 cases. Figure 8 is shown as ship's near-collision trajectory.

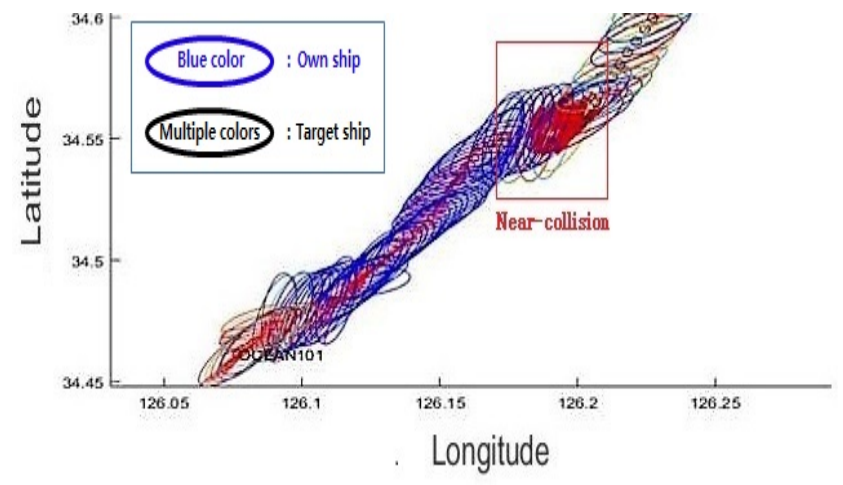

Figure 8: Ship near-collision trajectory

By extracting a total of 196 near-collision ships occurred in each level, we corresponded to the CRI of proposed level. DCPA and TCPA was extracted based on ship's trajectory near-collision data when near-collision by level occurred. At this time, the DCPA was non-dimensionalized by using ship length $L$, and the TCPA was non-dimensionalized by using ship length $L$ divided by the ship speed $V$. Table 4 shows the trajectory data of ship nearcollision by level.

Table 4: The trajectory data of ship near-collision by level

\begin{tabular}{|c|c|c|c|}
\hline Level & DCPA/ $\boldsymbol{L}$ & TCPA/ $(\boldsymbol{L} / \boldsymbol{V})$ & CRI \\
\hline \multirow{3}{*}{$\begin{array}{c}\text { Collision } \\
(\mathbf{C})\end{array}$} & 0.12 & 0.74 & 1.0 \\
\cline { 2 - 4 } & 0.09 & 1.93 & 1.0 \\
\cline { 2 - 4 } & 0.17 & 1.13 & 1.0 \\
\hline \multirow{3}{*}{$\begin{array}{c}\text { Dangerous } \\
\text { (D) }\end{array}$} & 0.48 & 0.49 & 0.66 \\
\cline { 2 - 4 } & 0.41 & 2.98 & 0.66 \\
\cline { 2 - 4 } & 0.68 & 4.41 & 0.66 \\
\hline \multirow{3}{*}{$\begin{array}{c}\text { Threat } \\
(\text { T) }\end{array}$} & 1.07 & 7.28 & 0.33 \\
\cline { 2 - 4 } & 1.06 & 9.89 & 0.33 \\
\hline \multirow{3}{*}{$\begin{array}{c}\text { Attention } \\
(\mathbf{A})\end{array}$} & 0.72 & 0.81 & 0.33 \\
\cline { 2 - 4 } & 1.29 & 7.22 & 0.1 \\
\cline { 2 - 4 } & 1.43 & 3.09 & 0.1 \\
\hline \multirow{2}{*}{} & 2.27 & 13.3 & 0.1 \\
\hline
\end{tabular}

\subsection{Inference Rule of Collision Risk}

\subsubsection{Structure of ANFIS}

The ANFIS[26] is one of the neuro fuzzy systems for the fuzzy modeling and control proposed by Jang. Configuration of inference rule of the collision risk was as follows. First step designated $\mathrm{DCPA} / L$ and TCPA $/(L / V)$ as input parameter, and the CRI as output parameter. At this time, DCPA $/ L$ and TCPA $/(L / V)$ were composed of a total 4 of MF(memberships function). Table 5 shows input and output parameter set in MF.
Table 5: Categorized input and output parameter

\begin{tabular}{|c|c|c|c|}
\hline \multirow{3}{*}{ No. } & \multicolumn{2}{|c|}{ Input } & Output \\
\hline & DCPA/L & TCPA $/(L / V)$ & CRI \\
\hline & Inputmf & Inputmf & Outputmf \\
\hline 1 & \multirow{4}{*}{ Collision } & Collision & Outputmf 1 \\
\hline 2 & & Dangerous & Outputmf 2 \\
\hline 3 & & Threat & Outputmf 3 \\
\hline 4 & & Attention & Outputmf 4 \\
\hline 5 & \multirow{4}{*}{ Dangerous } & Collision & Outputmf 5 \\
\hline 6 & & Dangerous & Outputmf 6 \\
\hline 7 & & Threat & Outputmf 7 \\
\hline 8 & & Attention & Outputmf 8 \\
\hline 9 & \multirow{4}{*}{ Threat } & Collision & Outputmf 9 \\
\hline 10 & & Dangerous & Outputmf 10 \\
\hline 11 & & Threat & Outputmf 11 \\
\hline 12 & & Attention & Outputmf 12 \\
\hline 13 & \multirow{4}{*}{ Attention } & Collision & Outputmf 13 \\
\hline 14 & & Dangerous & Outputmf 14 \\
\hline 15 & & Threat & Outputmf 15 \\
\hline 16 & & Attention & Outputmf 16 \\
\hline
\end{tabular}

Second step composed of fuzzy inference rule by learning input and output parameters via ANFIS. Figure 9 shows ANFIS structure configured by using MF of input and output parameters.

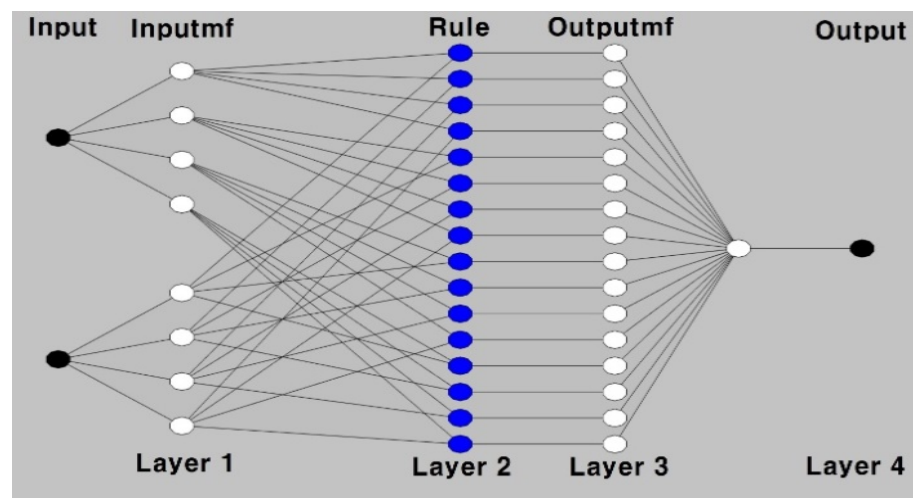

Figure 9: Structure of ANFIS

DCPA/ $L$ and $\mathrm{TCPA} /(L / V)$ were designated as premise parameter $x, y$ and CRI was designated as consequent parameter $f_{i}$. By using consequent coefficient $a, b, c$ inference rule was composed as shown in equation (4).

$$
\begin{gathered}
\text { Rule }_{i}: \text { If } x \text { is } \mu_{\left(\frac{D C P A}{L}\right) i} \text { and } y \text { is } \mu_{\left(\frac{T C P A}{\left(\frac{L}{V}\right)}\right) i} \\
\text { then } f_{i}=a_{i} x+b_{i} y+c
\end{gathered}
$$

\subsubsection{Inference Rule through Learning Algorithm}

The ANFIS can be trained by the backward propagation algorithm and the hybrid learning algorithm. In the backward propagation algorithm, the errors are propagated backward and the premise parameters are updated by gradient descent. At this time, consequent parameters are fixed. In the hybrid learning algorithm, the premise and consequent parameters are updated by least- 
squares method and gradient descent. In this study, we used the backward propagation algorithm for maintaining the CRI designated by level. Therefore, surface of CRI through learning by the backward propagation algorithm was represented non-linear as shown in Figure 10.

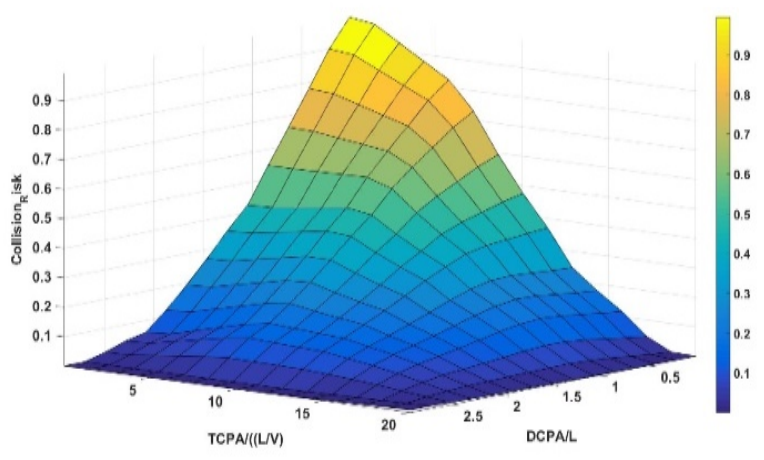

Figure 10: Surface of the CRI

Inference rule of the CRI proposed by learning near-collision data via ANFIS was presented in Table 6.

Table 6: Fuzzy inference rule for membership function

\begin{tabular}{|c|c|c|c|c|c|}
\hline \multirow{2}{*}{\multicolumn{2}{|c|}{ Division }} & \multicolumn{4}{|c|}{ DCPA $/ L$} \\
\hline & & $\mathrm{C}$ & D & $\mathbf{T}$ & $\mathbf{A}$ \\
\hline \multirow{4}{*}{ 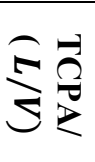 } & C & 0.994 & 0.773 & 0.477 & 0.021 \\
\hline & D & 0.777 & 0.662 & 0.401 & 0.017 \\
\hline & $\mathbf{T}$ & 0.395 & 0.423 & 0.335 & 0.015 \\
\hline & $\mathbf{A}$ & 0.062 & 0.246 & 0.152 & 0.011 \\
\hline
\end{tabular}

\section{Result and Discussion}

\subsection{Result}

To validate performance of the proposed fuzzy inference rule by comparing with the existing fuzzy rule, two ships navigating at Mokpo sea area were selected from AIS data. One of which was designated as own-ship and the other was designated as a target ship. An encounter situation and near-collision situation are presented in Figures 11 and Figure 12. When the encounter situation occurred within $10 \mathrm{~nm}$, own-ship begun calculating the CRI with DCPA and TCPA. The CRI calculated from four types of inference rule was presented in Table 7 and Figure 13.

At the initial encounter situation between own-ship and a target ship, the FIS[12], FIS-VCD[13], FIS-SC[19] and FIS-NC proposed in section III indicated the CRI 0.29, 0.67, 0.32 and 0.11, respectively.

When it comes to TCPA and distance, the FIS-SC and the FIS$\mathrm{NC}$ were gradually increased until near-collision situation according to reduction of TCPA and distance. Whereas, the FIS and the FIS-VCD were not gradually increased until near-collision situation. In case of the FIS, after it obtained the CRI until 0.94, the same CRI was kept until near-collision situation. In case of the FIS-VCD, unlike the FIS, the FIS-SC and the FIS-NC, it depended on how much the VCD was obtained due to input parameter DCPA,
TCPA and VCD. As shown in Table 7, as the VCD got closer at 0 , the CRI was increased.

When it comes to a point of time for action of collision avoidance of a give-way ship, distance for action of collision avoidance via the FIS, the FIS-VCD, the FIS-SC and FIS-NC represented about $7.2 \mathrm{~nm}$, about $9.8 \mathrm{~nm}$, about $6.1 \mathrm{~nm}$ and about $7.7 \mathrm{~nm}$, respectively. At this time, TCPA represented about 10.7 minutes, 15.8 minutes, 7.7 minutes and 11.7 minutes, respectively.

When it comes to a point of time for action of collision avoidance of a stand-on ship, distance for action of collision avoidance via the FIS, the FIS-VCD, the FIS-SC and FIS-NC represented about $5.1 \mathrm{~nm}$, about $7.2 \mathrm{~nm}$, about $1.7 \mathrm{~nm}$ and about $6.1 \mathrm{~nm}$, respectively. At this time, TCPA represented about 7.4 minutes, 10.7 minutes, 2.5 minutes and 7.7 minutes, respectively.

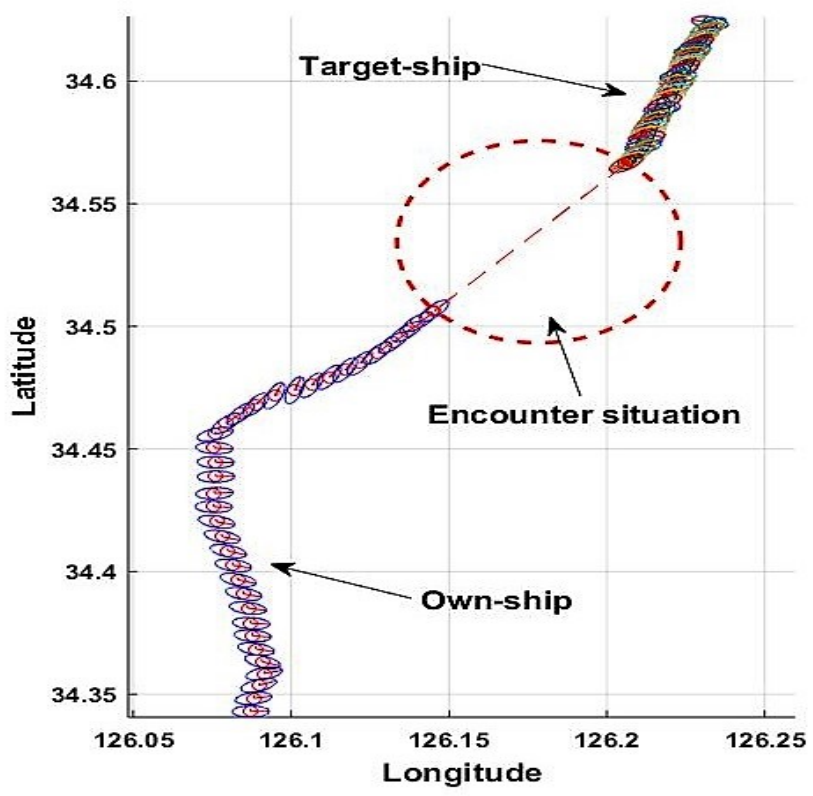

Figure 11: Encounter situation

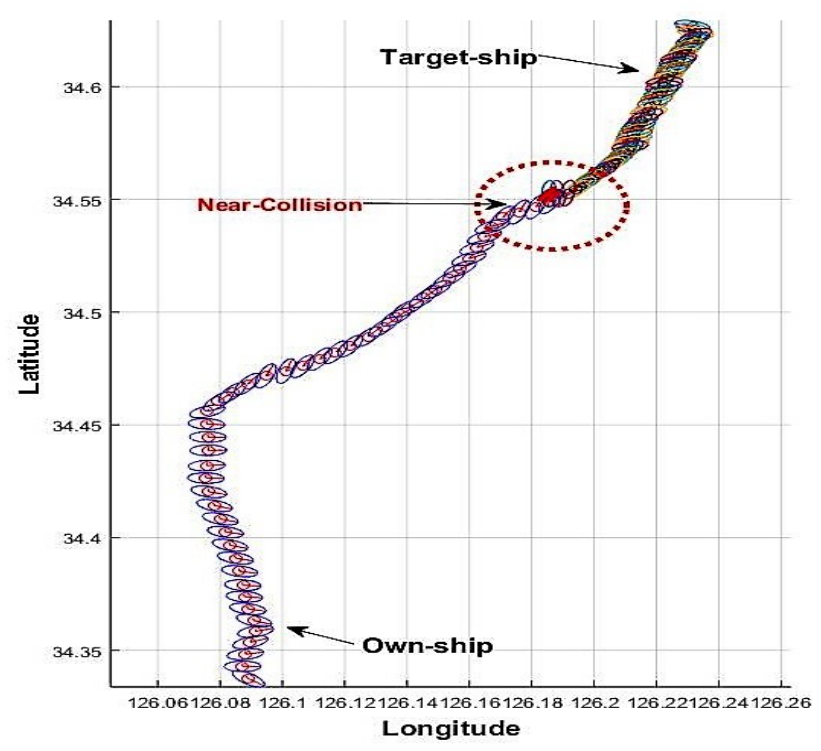

Figure 12: Near-collision situation 
Ho Namgung / Advances in Science, Technology and Engineering Systems Journal Vol. 4, No. 4, 152-160 (2019)

Table 7: Comparison with the different CRI according to TCPA and distance

\begin{tabular}{|c|c|c|c|c|c|c|c|}
\hline \multirow{2}{*}{$\begin{array}{l}\text { Distance } \\
\text { (nm) }\end{array}$} & \multirow{2}{*}{$\begin{array}{c}\text { TCPA } \\
\text { (minute) }\end{array}$} & \multirow{2}{*}{$\begin{array}{c}\text { VCD } \\
\text { (degree) }\end{array}$} & \multicolumn{4}{|c|}{ Collision Risk Index } & \multirow{2}{*}{$\begin{array}{c}\text { A point of time } \\
\text { for collision avoidance }\end{array}$} \\
\hline & & & FIS & FIS-VCD & FIS-SC & FIS-NC & \\
\hline 9.8 & 15.8 & - & 0.29 & 0.67 & 0.32 & 0.11 & FIS-VCD(give-way) \\
\hline 9.3 & 14.5 & 1.2 & 0.39 & 0.71 & 0.36 & 0.17 & \\
\hline 8.9 & 13.6 & 0 & 0.45 & 0.73 & 0.38 & 0.21 & \\
\hline 8.4 & 13.1 & 2.2 & 0.48 & 0.74 & 0.41 & 0.24 & \\
\hline 8.1 & 12.4 & 6.5 & 0.51 & 0.77 & 0.44 & 0.31 & \\
\hline 7.7 & 11.7 & 7.8 & 0.54 & 0.78 & 0.46 & 0.34 & FIS-NC(give-away) \\
\hline 7.2 & 10.7 & 0.3 & 0.62 & 0.8 & 0.49 & 0.42 & FIS(give-way), FIS-VCD(stand-on) \\
\hline 6.9 & 10.1 & 0.5 & 0.65 & 0.81 & 0.51 & 0.46 & \\
\hline 6.4 & 8.3 & 0.3 & 0.74 & 0.84 & 0.58 & 0.61 & \\
\hline 6.1 & 7.7 & 0.4 & 0.77 & 0.86 & 0.61 & 0.67 & FIS-SC(give-way), FIS-NC(stand-on) \\
\hline 5.5 & 7.6 & 2.8 & 0.78 & 0.84 & 0.62 & 0.68 & \\
\hline 5.1 & 7.4 & 0.2 & 0.8 & 0.87 & 0.63 & 0.71 & FIS(stand-on) \\
\hline 4.6 & 6.8 & 3.5 & 0.8 & 0.83 & 0.66 & 0.77 & \\
\hline 4.2 & 6.1 & 1.7 & 0.81 & 0.87 & 0.68 & 0.79 & \\
\hline 3.8 & 5.4 & 2.6 & 0.83 & 0.84 & 0.7 & 0.82 & \\
\hline 3.3 & 4.9 & 4.6 & 0.85 & 0.81 & 0.72 & 0.84 & \\
\hline 2.9 & 4.4 & 1.3 & 0.88 & 0.88 & 0.75 & 0.86 & \\
\hline 2.5 & 3.7 & 1.4 & 0.93 & 0.87 & 0.77 & 0.89 & \\
\hline 2.1 & 3.1 & 6 & 0.94 & 0.81 & 0.79 & 0.92 & \\
\hline 1.7 & 2.5 & 3.2 & 0.94 & 0.83 & 0.8 & 0.94 & FIS-SC(stand-on) \\
\hline 1.3 & 2.2 & 0.1 & 0.94 & 0.93 & 0.84 & 0.95 & \\
\hline 0.9 & 1.5 & 0 & 0.94 & 0.94 & 0.83 & 0.97 & \\
\hline 0.4 & 0.7 & 2.6 & 0.94 & 0.84 & 0.87 & 0.98 & \\
\hline 0.2 & 0.1 & 0.4 & 0.94 & 0.91 & 0.92 & 0.99 & Near-Collision \\
\hline
\end{tabular}

FIS: Fuzzy Inference System; FIS-VCD: Fuzzy Inference System based on VCD; FIS-SC: Fuzzy Inference System based on Ship's Characteristic; FIS-NC: Fuzzy Inference System based on Near-Collision

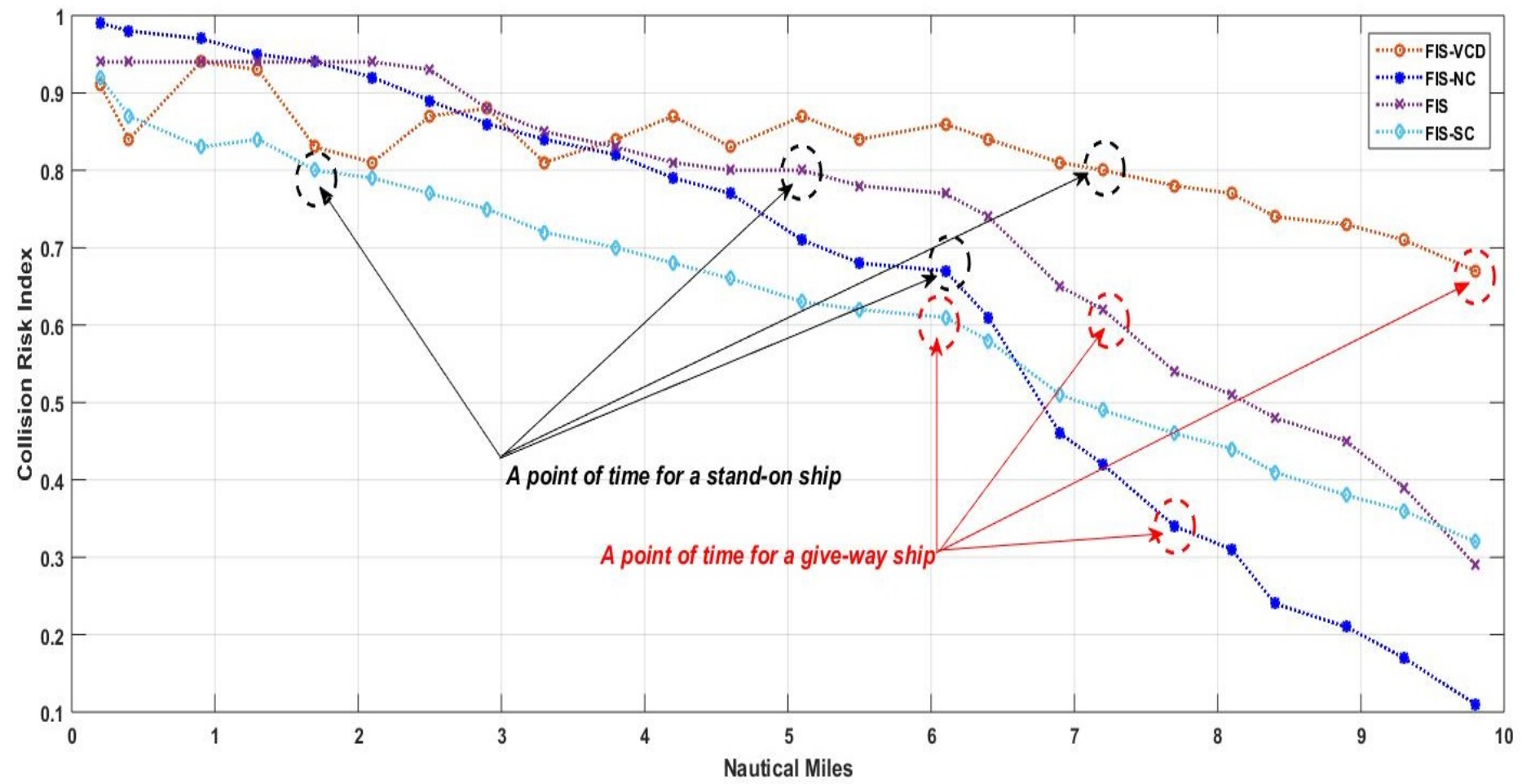

Figure 13: Comparison with the different CRI corresponding to distance 


\subsection{Discussion}

In section 4.1, it could be seen that the exiting rule[12,13,19] and the proposed rule were able to obtain the CRI in the encounter situation between own-ship and a target ship according to values of input parameter. However, a point of time for action of collision avoidance was different according to type of the encounter situation. In case of a give-way ship, the FIS, the FIS-VCD and the FIS-SC defined that own-ship must take an action when the CRI exceeded more than 0.6. In case of a stand-on ship, own-ship must take an action for collision avoidance when the CRI exceeded more than 0.8. On the other hand, when the CRI exceeded more than 0.33 , the FIS-NC proposed that a give-way ship must take an action for collision avoidance. In case of a stand-on ship in the FIS$\mathrm{NC}$, a point of time for collision avoidance was when the CRI was more than 0.66 . Therefore, in this section, a point of time for action of collision avoidance via the FIS, the FIS-VCD, the FIS-SC and the FIS-NC were discussed according to the "A guide to the collision Avoidance Rules[25]", as well as a review of the various values obtained from inference rules.

According to [25], it states that ship should take an action for collision avoidance within about 5 to 10 minutes of TCPA or within about 2 to $3 \mathrm{~nm}$ of minimum distance. As shown in Table 7 and Figure 13, a give-way ship using the FIS, the FIS-VCD, the FIS-SC and the FIS-NC can obtain outer distance 2 to $3 \mathrm{~nm}$ and enough TCPA for taking an action. whereas, in case of a stand-on ship, the only the FIS-SC didn't obtain the requested distance and TCPA. it means that ship using the FIS-SC have no choice but to take into consideration collision risk at all times.

In terms of the CRI expression, even though the FIS had enough distance and TCPA until near-collision situation, it indicated the same CRI from 0.94 to near-collision situation. In case of the FIS-VCD, it relied on the only VCD. For this reason, unlike the FIS, FIS-SC and FIS-NC, the only the FIS-VCD already exceeded more than threshold at the initial encounter situation. On the other hand, the FIS-SC and the FIS-NC expressed the various CRI according to input parameters. It means that the CRI calculated from the FIS-SC and the FIS-NC reflected original information(DCPA, TCPA) well. Accordingly, because priority of multiple ships can be designated via the various CRI, these would be possible to not only take an appropriated action of collision avoidance between ships, but also among multiple ships.

For this reason, a ship using the FIS-NC can take an suitable action in any encounter situations because it reflects all of aspects, i.e., appropriated distance and TCPA according to the various CRI. However, it didn't reflect various factors, e.g., weather condition, ship size, congestion of navigation area and so on.

\section{Conclusion}

Although the FIS using DCPA and TCPA have been reported previously, they have largely relied on the use of either interviews of navigators or ship's characteristic in virtual navigation situation. These approaches tend to have the limitation not reflecting on information of actual collision situation between ships. Therefore, in this paper, we proposed the fuzzy inference rule based on nearcollision via ANFIS by applying an action of collision avoidance corresponding to the CRI by level. For a configuration of fuzzy inference rule, steps was conducted as follows. An action of collision avoidance was defined, and distance to conduct an action of collision avoidance was set; (i). By enlarging ship domain based on designated distance by level, DCPA, TCPA and CRI were extracted when overlapped; (ii). Fuzzy inference rule was proposed by learning near-collision data via ANFIS; (iii). The results of applying proposed fuzzy inference rule to actual navigation area expressed the various CRI corresponding to the required distance and TCPA in order that navigators can make a decision appropriately. Accordingly, the proposed fuzzy inference rule not only overcame these issues, but also offered performance more outstanding than the existing fuzzy inference rule. However, it didn't reflect weather condition, ship size, congestion of navigation area, and so on. In further study, it is required to improve and validate the inference rule of the CRI taking consideration into drawbacks.

\section{Conflict of Interest}

The author declares no conflict of interest.

\section{References}

[1] Korean Maritime Safety Tribunal, “Annual Report of Marine Accident," 2018.

[2] Fujii, J., Tanaka, K., "Traffic capacity," Journal of Navigation, 24, 543-552, 1971. https://doi.org/10.1017/S0373463300022384

[3] Goodwin, E.M., "A statistical study of ship domains," Journal of Navigation, 28, 328-344, 1975. https://doi.org/10.1017/S0373463300041230

[4] Davis, P.V., Dove, M.J., Stockel, C.T., "A computer simulation of marine traffic using domains and arenas,” Journal of Navigation, 33, 215-222, 1980. https://doi.org/10.1017/S0373463300035220

[5] Coldwell, T.G., "Marine traffic behavior in restricted waters," Journal of Navigation, 36, 431-444, 1983. https://doi.org/10.1017/S0373463300039783

[6] Jensen, T.K., Hansen, M.G., Lehn-Schiøler, T., Melchild, K., Rasmussen, F.M., Ennemark, F., "Free flow-efficiency of a one-way traffic lane between two pylons," Journal of Navigation, 66, 941-951, 2013. https://doi.org/10.1017/S0373463313000362

[7] Van Iperen, W.H., "Classifying ship encounters to monitor traffic safety on the North sea from AIS data,” TransNav, Int. J. Mar. Navig. Saf. Sea Transp, 9 (1), 51-58, 2015. https://doi.org/10.12716/1001.09.01.06

[8] Pietrzykowski, Z., Uriasz, J., "The ship domain - a criterion of navigational safety assessment in an open sea area," Journal of Navigation, 62, 93-108, 2009. https://doi.org/10.1017/S0373463308005018

[9] Wang, N., Meng, X., Xu, Q., Wang, Z., "An intelligent spatial collision risk based on the quaternion ship domain," Journal of Navigation, 63, 733-749, 2010. https://doi.org/10.1017/S0373463310000202

[10] Wang, N., 2013. "A novel analytical framework for dynamic quaternion ship domains," Journal of Navigation, 66, 265-281, 2013. https://doi.org/10.1017/S0373463312000483

[11] Hasegawa, K., Kouzyki, A., Muramatsu, T., Komine, H., and Watabe, Y., "Ship Auto-navigation Fuzzy Expert System (SAFES)," Journal of the Society of Naval Architecture of Japan, 166, 1989. https://doi.org/10.2534/jjasnaoe1968.1989.166_445

[12] Lee, Han-Jin and Rhee, Key-Pyo, "Development of collision avoidance system by using expert system and search algorithm," Journal of International Shipbuilding Progress 48, 197-212, 2001.

[13] Eun-kyoung Kim, II-kweon Kang, and Yong-gi Kim, "Collision Risk Decision System for Collision Avoidance,” 11(6), 524-527, 2001.

[14] Nam-Sun Son, Sun-Young Kim, and Chan-Soo Lee, "On the Monitoring System of Collision Risks Among Multiple Ships," Annual of Navigation, 19(1), 2012. https://doi.org/10.2478/v10367-012-0012-x

[15] Ahmad C. Bukhari, Inara Tusseyeva, Byung-Gil Lee, and Yong-Gi Kim, "An intelligent real-time multi-vessel collision risk assessment system from VTS view point based on fuzzy inference system," Expert System with Applications, 40, 12201230, 2013. https://doi.org/10.1016/j.eswa.2012.08.016

[16] Mira Yi, "Design of the Neuro-Fuzzy based System for Analyzing Collision Avoidance Measures of Ships," Journal of Korean Institute of Intelligent Systems, 27(2), 113-118, 2017. https://doi.org/10.5391/JKIIS.2017.27.2.113

[17] Nam-Sun Son and Sun-Young Kim, "On the sea trial test for the validation of an autonomous collision avoidance system of unmanned surface vehicle, ARAGON," OCEANS 2018 MTS/IEEE Charleston. https://doi.org/10.1109/OCEANS.2018.8604803

[18] Ho Namgung, Jung Sik Jeong, Jo-Cheon Choi, Geun Woong Kim, and JooSung Kim, "Design of Information Exchange Handling System for Safe 
Navigation of Autonomous Ship," Journal of Korean Institute of Intelligent Systems, 29(1), 42-49, February, 2019. https://doi.org/ 10.5391/JKIIS.2019.29.1.42

[19] Jin-Hyeong Ahn, Key-Pyo Rhee, and Young-Jun You, "A study on the collision avoidance of a ship using neural networks and fuzzy logic," Applied Ocean Research, 37, 162-173, 2012. https://doi.org/10.1016/j.apor.2012.05.008

[20] Inoue, K. and Kawase, M., "Innovative Probabilistic Prediction of Accident Occurrence,” Int. J. Marine Nav. \& Safety Sea Trans., 1(1), 19-22, 2007.

[21] Zhang, W., F. Goelandt, P.Kujala, and Y.Wang, "An Advanced Method for Detecting Possible Near Miss Ship Collisions from AIS data," Ocean Eng., 124, 141-156, 2016. https://doi.org/10.1016/j.oceaneng.2016.07.059

[22] Rafal Szlapczynski, "A Framework of a ships domain-based near-miss detection method using mamdani neuro-fuzzy classification," POLISH MARITIME RESEARCH Special Issue, 25, 14-21, 2018. https://doi.org/10.2478/pomr-2018-0017

[23] IMO, International Regulations for Preventing Collisions at Sea, COLREGS, 1972.

[24] Y.S, Lee, J.M. Park, and Y.J. Lee, "A Study on the Initial Action of Navigators to Avoid Risk of Collision at Sea," Journal of Korean Navigation and Port Research, 38, 2014. https://doi.org/10.5394/KINPR.2014.38.4.327

[25] Cockcroft, A. N. and Lameijer, J. N. F., "A Guide to the Collision Avoidance Rules,” Butterworth Heinemann, Oxford, UK, 2011.

[26] Jang JR, "Adaptive-network based fuzzy inference system," IEEE Transactions on systems, Man and Cybernetics, 1993. 